\title{
Classic Studies on the Interaction of Cocaine and the Dopamine Transporter
}

\author{
Vivek Verma \\ Department of Neuroscience, University of Pittsburgh, Pittsburgh, PA, USA
}

\begin{abstract}
The dopamine transporter is responsible for recycling dopamine after release. Inhibitors of the dopamine transporter, such as cocaine, will stop the reuptake of dopamine and allow it to stay extracellularly, causing prominent changes at the molecular, cellular, and behavioral levels. There is much left to be known about the mechanism and site(s) of binding, as well as the effect that cocaine administration does to dopamine transporter-cocaine binding sites and gene expression which also plays a strong role in cocaine abusers and their behavioral characteristics. Thus, if more light is shed on the dopamine transporter-cocaine interaction, treatments for addiction and even other diseases of the dopaminergic system may not be too far ahead. As today's ongoing research expands on the shoulders of classic research done in the 1990s and 2000s, the foundation of core research done in that time period will be reviewed, which forms the basis of today's work and tomorrow's therapies.
\end{abstract}

KEY WORDS: Cocaine; Dopamine plasma membrane transport proteins; Dopamine; Substance addiction; Parkinson disease; Protein-protein interaction.

\section{INTRODUCTION}

Dopamine (DA) is a neurotransmitter that projects to many regions of the brain and originates in the substantia nigra and the ventral tegmental area (VTA). Physiologically, DA is involved in many important functions, including movement, cognition, and reward. In fact, a disruption of, or injury to the dopaminergic system in the brain and deficit of DA has been shown to lead to many predictable symptoms. Parkinson's disease (PD)-like symptoms can appear, such as bradykinesia and tremor, and there is a marked change in cognitive function and mood, similar to schizophrenia, depression, and dementia. ${ }^{1)}$ Levels of extracellular DA are affected by the activity and regulation of the dopamine transporter (DAT), which is located at the presynaptic nerve terminal and recycles extracellular DA back into the presynaptic neuron, whereupon it may be repackaged into synaptic vesicles by the vesicular monoamine transporter or degraded by enzymes such as monoamine oxidase (MAO) or catechol-O-methyl transferase. This reusing of DA is a key step for regulation, and many

\footnotetext{
Received: December 24, 2014 / Revised: May 29, 2015

Accepted: June 5, 2015

Address for correspondence: Vivek Verma, MD

Department of Neuroscience, University of Pittsburgh, A206

Langley Hall, Pittsburgh, PA 15260, USA

Tel: +1-724-991-3868, Fax: +1-412-624-9198

E-mail: vivek333@gmail.com
}

pharmacological methods to treat a lack or abundance of DA have been targeted at DAT itself. For example, the drug Ritalin (methylphenidate) is a potent blocker of DAT, thus increasing the concentration of DA in the extracellular space and increasing the probability of DA of binding to its receptor(s) and causing the desired effect. ${ }^{2}$ Another chemical that blocks DAT and other monoamine transporters $^{3-6)}$ is cocaine, ${ }^{7,8)}$ a potent and highly addictive drug, which was commonly abused in the 1980s and 1990s (and still is today). Cocaine too blocks DAT and increases the availability of DA, thereby causing symptoms of increased DA - elevated energy and arousal. ${ }^{9,10)}$ In addition, cocaine increases DA in the VTA, which is widely known as one of the reward centers of the brain. ${ }^{11-13)}$ Thus, cocaine gives rise to an experience of pleasure and reward. It is thought that this pleasure and reward is a major mechanism as to why cocaine is an extremely addictive drug and why users find cocaine addicting. ${ }^{14)}$ Cocaine is also thought to be addictive because of its dose-dependent action on DAT; greater cocaine levels yield even greater extracellular DA levels, leading to yet a greater feeling of pleasure and reward in the brain. ${ }^{15)}$ In order to understand cocaine's interactions and effects on DAT, we must first start from the basic function and pharmacology of DAT, expand on how cocaine interacts with DAT, and then look at the effects elicited by cocaine use (and abuse) from the perspective of DAT regulation.

(c) This is an Open-Access article distributed under the terms of the Creative Commons Attribution Non-Commercial License (http://creativecommons.org/licenses/by-nc/4.0) which permits unrestricted non-commercial use, distribution, and reproduction in any medium, provided the original work is properly cited. 


\section{MAIN SUBJECTS}

\section{Structure, Function, and Pharmacology of DAT}

DAT is a specific marker for dopaminergic neurons because it is uniquely expressed on neurons that use DA as a neurotransmitter. DAT exists in the plasma membrane as an oligomeric complex ${ }^{16-18)}$ and is made up of twelve transmembrane regions (TMR), with loops between TMRs (including a particularly large extracellular one between TMRs 3 and 4). TMRs 9-12 and/or 1-3 may be involved with the interaction of DA during reuptake. However, the DAT antagonist cocaine has been found based on site-directed mutagenesis studies to bind to different regions of DAT, having affinity for TMRs 5-8. ${ }^{19-21)}$ Fig. 1 demonstrates the structure of DAT. ${ }^{22)}$

The structure of DAT and its relationship with cocaine can reveal quite a lot about cocaine's addictiveness. The implications for having different substrate and agonist binding sites are that there may be little competitive binding and that cocaine can exert its effects even in the presence of normal DA (its binding would not be controlled by DA but by itself only). These theories may explain the potency of the cocaine-induced response as well as its addictiveness. $^{23)}$

Interestingly, another aspect of addiction has been suggested to be attributed to the clustering of DAT molecules. Giros et al. ${ }^{24)}$ reported that clustering the molecules increases reuptake efficiency. The study associates the clustering to the bonding of neighboring TMRs 2 and 9. This finding implies that if many or all of these uptake receptors would be blocked, then there would be a large in-

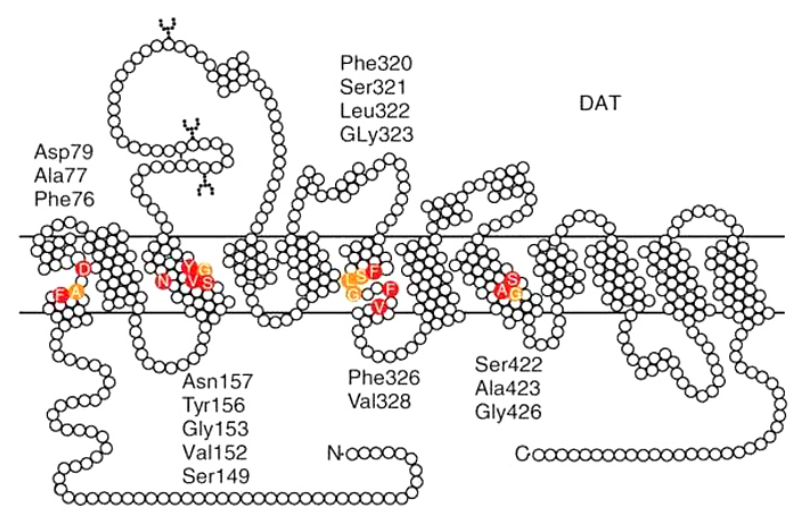

Fig. 1. Structure of the human dopamine transporter. Colored circles denote amino acids shown molecularly to interact with dopamine and/or the cocaine analog WIN35428 with the backbone (orange) or side chains (red). Reproduced from Beuming et al. ${ }^{22}$ (Nat Neurosci 2008;1 1:780-789) with permission. crease in extracellular DA because of the severely reduced efficiency of reuptake. Keeping this in mind, we can thus see from a molecular basis that chronic usage of cocaine (or other DAT blockers) can be a powerful substance for addiction.

Many of DAT's chemical interactions can be used to mimic certain neuropathologies. In addition to cocaine, the substance 6-hydroxydopamine also exerts its toxic effects by entering neurons through DAT, thus leading to selective destruction of dopaminergic neurons and providing a relatively good model of PD.

Other instances of DAT's chemical interactions have been discovered by accident throughout the course of time. A well-known example of this case is 1-methyl-4-phenylpyridinium (MPP + ). In the 1980s, heroin users in California were suddenly coming down with PD-like symptoms. Scientists made efforts to determine what was causing this illness and hoped that whatever was causing the illness may be linked to the pathophysiology of PD. What scientists found was that the heroin was contaminated by a substance called 1-methyl-4-phenyl1,2,3,6-tetrahydropyridine, better known as MPTP. MPTP would cross the blood-brain barrier and get into the neuron through DAT and interact with MAO to make a chemical called MPP + . MPP + would then go on to interact with complex I of the mitochondrial electron transport chain, poisoning it. Thus, the neuron would experience a deficit in adenosine triphosphate. In addition, inhibiting complex I causes the formation of oxygen free radicals, which then go on to interact with nitric oxide and form the powerful peroxynitrite free radical. The dopaminergic DAT+ cell would then go on to initiate apoptosis and thus cause PD-like symptoms. ${ }^{25-29)}$ Interestingly, addition of the neuronal nitric oxide blocker 7-nitrindazole to neurons with MPP+ treatment results in neuroprotection and decreased neuron loss, likely due to the inhibition of nitric oxide production and interference of peroxynitrite-based cell damage. $^{30)}$ Moreover, DAT $-/-$ knockout mice did not show effects of MPTP poisoning, ${ }^{31)}$ thus suggesting that DAT is an essential component of the sequence of events that leads to apoptosis. Cocaine itself was shown by Mayer et al. ${ }^{32)}$ to block DAT, MPTP intake, and MPP + -based cell damage.

Despite the intriguing number of recent studies being done on pharmacological manipulations of DAT, we know relatively little about the molecular basis of DA translocation. There have been many residues that have been implicated in DAT reuptake function. One promising example of the actual reuptake function of DAT has been 
postulated to be mediated by prolines located in the transporter, ${ }^{33)}$ causing mobility of the substrate and shuttling it into the neuron. In addition, another study has reported critical involvement of charged amino acids in the TMR as facilitating DA reuptake. ${ }^{34)}$ Other reports have suggested the involvement of $\mathrm{Asp}^{79}$ (TMR 1); $\mathrm{Ser}^{351}, \mathrm{Ser}^{354}, \mathrm{Ser}^{357}$, and $\mathrm{Ser}^{360}$ in TMR 7; as well as $\mathrm{Ser}^{528}, \mathrm{Ser}^{539}$, and $\mathrm{Phe}^{534}$ in TMR 11. ${ }^{35,36)}$ Our awareness of DAT structure and function would certainly benefit from more studies in the future.

Much of what we know about DAT function comes from studies in which DAT structure and/or function has been changed by some method. To begin with, it is known that DAT is dependent on $\mathrm{Na}+/ \mathrm{Cl}-$ symport into the cell and is reversible if ionic gradients are reversed. ${ }^{37,38)}$ These studies suggest that DA reuptake is driven, at least partially, by the energy from $\mathrm{Na}+$ and $\mathrm{Cl}-$ concentration gradients. Furthermore, DAT's direction of activity (DA influx or efflux) is dependent on the direction of $\mathrm{Na}+$ and $\mathrm{Cl}-$ ion flow (thus being directly dependent on whether the bulk of ions are intra- or extracellular).

DAT function has also been shown to be changed by phosphorylation. Protein kinases such as the isoforms of protein kinase $\mathrm{C}$ (PKC) can phosphorylate DAT on N-terminal sites, perhaps also regulated by protein phosphatases. ${ }^{39-43)}$ This causes a decrease of functional DATs (as seen also with serotonin transporters [SERTs]) on the cell membrane and thus a reduction in DA influx. ${ }^{44-49)}$ Other important regulatory mechanisms for DAT involve their interactions with various proteins. ${ }^{50)}$ Thus we see an important regulation of DAT that may serve as an activity-dependent mechanism of DA recycling.

\section{The DAT-Cocaine Interaction}

The interaction between cocaine and the DAT is an important one that has implications for homeostatic neurotransmitter balance as well as addiction and behavior. The interaction is the result of the high affinity $\left(\mathrm{K}_{\mathrm{i}}\right.$ anywhere between 0.2 to $0.6 \mu \mathrm{M}$ ) interaction between cocaine and DAT. $^{2,51,52)}$ The high affinity interaction as well as cocaine's addictiveness implies that the blockade of DAT by cocaine is quite an efficient one. Fig. 2 illustrates a proposed mechanism of DAT interaction with a cocaine analog. ${ }^{22)}$

Many cocaine-DAT interaction sites have been elucidated by the binding of the cocaine analog, $3 \beta$ (4- ${ }^{125}$ iodophenyl)-tropane-2-carboxylic acid methyl ester ([ $\left.\left.{ }^{125} \mathrm{I}\right] \mathrm{RTI}-55\right)$. There is an extremely high affinity between [ ${ }^{125}$ I]RTI-55 and DAT, and so it has been the focus of use for revealing even minor cocaine binding sites. ${ }^{53-57)}$
These weak interactions may play a substantial role in the high affinity of cocaine-DAT binding and efficient DAT inhibition.

Binding of DAT inhibitors to the DAT in isolated cells has many requirements, one of which is the presence of a target $\mathrm{Na}+$ concentration between 20 and $50 \mathrm{mM}^{58)}$ This study scrutinized individual and isolated cells and controlled their environment's $\mathrm{Na}+$ concentration, thus pointing out that the results of the study are true for isolated cells in non-physiological conditions. From a physiological standpoint, neurons are bathed in fluid that is much richer in $\mathrm{Na}+$. Indeed, the neuron in vivo has inputs coming in from not only $\mathrm{Na}+$, but also other anions, paracrine signaling, and/or neurotransmission; all of these are theoretically able to change the responsiveness of a neuron for $\mathrm{Na}+$ and allow cocaine to bind. Since cocaine has such a strong effect even in humans, it must bind to the DAT regardless of the increases sodium concentration. The important thing to be mentioned here is that $\mathrm{Na}+$ is capable of altering DAT-DAT inhibitor binding, and any fluxes in $\mathrm{Na}+$ would also change the affinity/binding of cocaine for the DAT.

In an effort to explain this result, the authors of Chen et $a l .{ }^{59)}$ point out that $\mathrm{Na}+$ could induce a change in DAT conformation and thus alter binding of DAT inhibitors such as cocaine. The study shows that $\mathrm{Na}+$ causes a

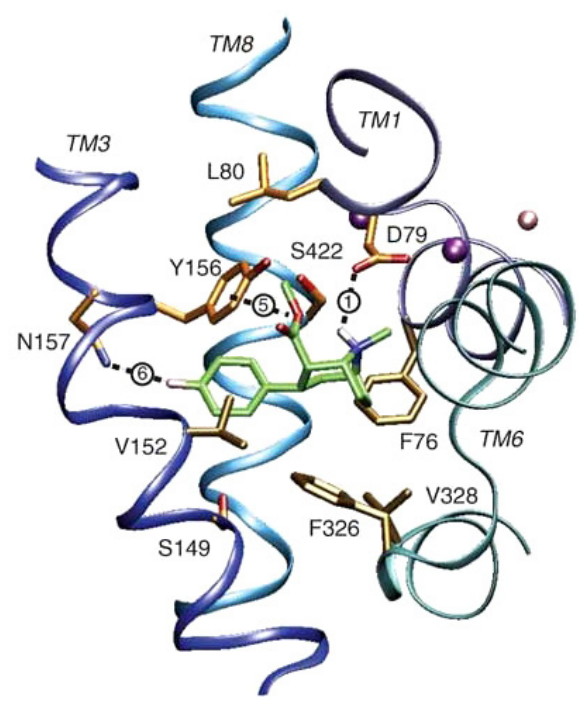

Fig. 2. Proposed interaction between the cocaine analog WIN35428 and the dopamine transporter. Selected interactions include the tertiary amine of WIN35428 and $\operatorname{Asp}^{79}$ (1), the $2 \beta$ methylester moiety of WIN35428 and Tyr ${ }^{156}$ (5), and WIN35428's fluoride atomic interaction with the nitrogen in $\mathrm{Asn}^{157}$ (6). Reproduced from Beuming et al. ${ }^{22)}$ (Nat Neurosci 2008; 1 1:780-789) with permission. 
change in DAT conformation such that the binding of multiple DAT inhibitors is energetically favorable. In addition, cocaine specifically can bind to DAT with greater affinity in the presence of $\mathrm{Na}+$. Therefore, there is no direct evidence that $\mathrm{Na}+$ can act on cocaine itself, but it rather acts on DAT, thereby impacting many of DAT's protein-protein interactions, signaling molecules, and inhibitors (a widespread influence).

Based on site-directed mutagenesis studies, the region in which cocaine binds to DAT is thought to be anywhere between TMRs $5-8 ;^{19,21)}$ however, another study argues that TMR 6 is the critical link between the cocaine and DAT interaction. ${ }^{60)}$ Cocaine may cover TMR 6, thus blocking the part of the DAT that is responsible for changing conformation and allowing DA translocation into the synaptosome. Thus, pharmacologically blocking TMR 6 may revert the effects of cocaine on dopaminergic neurons.

In addition to specific regions of DAT that cocaine is thought to bind to, there have been many studies relating binding and effector sites for cocaine to single amino acids. ${ }^{61-63)}$ All over the DAT protein, several amino acids have been shown to be critical to the binding and action of cocaine. Asp ${ }^{79}$ (located in TMR 1) has been shown ${ }^{33,64)}$ to be important for cocaine binding and recognition; furthermore, mutating $\mathrm{Asp}^{313}$ (extracellular loop between TMRs 5 and 6) changes selectivity for cocaine analogs, thus highlighting the role of aspartate in having an interaction of cocaine in more than one instance. ${ }^{65,66)}$

In addition, other amino acid mutations result in different effects with respect to cocaine and other substrate binding. Like mutating Asp ${ }^{313}$, mutating $\operatorname{Trp}^{555}$ (extracellular loop between TMRs 11 and 12) also changes DAT's selectivity for cocaine analogs. ${ }^{67)}$ However, mutation of Lys $^{264}$ (intracellular loop between TMRs 4 and 5) decreases affinity for cocaine as well as DA uptake. ${ }^{68)}$ This can be juxtaposed with the mutations of $\mathrm{Phe}^{154}$ and $\mathrm{Phe}^{456}$ (TMRs 3 and 9, respectively), which result in a decrease in cocaine binding along with no changes in DA transport. ${ }^{69)}$ Other instances ${ }^{36,70-74)}$ of mutations in single amino acids yields a potential importance of $\mathrm{Phe}^{76}$ (TMR 1), $\mathrm{Val}^{152}$ (TMR 3), Tyrr $^{156}$ (TMR 3), $\operatorname{Tyr}^{252}$ (TMR 4), Tyr ${ }^{274}$ (TMR 5), and $\mathrm{Phe}^{534}$ (TMR 11). Collectively, these DAT mutation studies suggest that function of DAT can be scrutinized even at the amino acid level, and that certain amino acid function is critical to DAT function, cocaine binding, and DA reuptake. Thus, if genetic mutations of DAT were to occur by chance in organisms, their responsiveness to cocaine and their natural regulation of DA in the extracellular space may be impaired. Even with the sub- stantial amounts of data present on the effects of individual amino acids on cocaine and/or DA binding, it is wise to take site-directed mutagenesis studies with skepticism. Mutating even one amino acid can potentially cause the entire conformation (and thus, the function) of DAT to change, thus changing affinity and binding to DA and/or cocaine.

Taken together, the DAT-cocaine interaction is an intricate one. It is possible that cocaine may interact with one region of DAT and cause a strong enough interaction such that the protein is conformationally changed. This would in turn cause more binding sites to be revealed, eventually leading to multiple binding sites between DAT and cocaine being uncovered and thus the blockage of DA influx. Thus, it is possible that cocaine can act on many DAT sites but the actual physiological binding sites would depend on the order of binding. If true, identifying the cocaine binding sequence may be a difficult task and would require much research.

The molecular interaction between cocaine and the DAT is vital to the effects of reward. DAT-knockout mice still self-administer cocaine and show a conditioned place preference for cocaine; this seems counterintuitive but is thought to occur because of cocaine's ability to inhibit norepinephrine transporter (NET) and SERT and cause increased extracellular DA. ${ }^{75-79)}$ In addition, knocking out DAT completely may result in a substantial imbalance in the entire dopaminergic system of the brain ${ }^{80,81)}$ and even compensation by other dopaminergic tributaries in the brain. ${ }^{82-84)}$ To circumvent these problems as much as possible, a knock-in mouse line was created in one report by a triple mutation in the DAT gene; the mice expressed a functional DAT but were insensitive to cocaine. ${ }^{85)}$ The DAT levels in the mice were not significantly changed from their wild-type counterparts, and neurons from both mice were capable of firing action potentials at the same frequency. Moreover, the authors showed a functional equivalency in $\mathrm{D}_{2}$ receptors of both mice, further suggesting the minimization of dopaminergic imbalance (as had happened with DAT-knockout mice) in the knock-in mice.

It was found in the same report that cocaine sensitivity was 89 -fold lower in the knock-in mice as measured by voltammetry, patch clamping, in vivo microdialysis, and DA uptake assays. More importantly, there was no conditioned place preference-based reward and no elevated extracellular DA in the nucleus accumbens of cocaine-insensitive mice, as well as no increased locomotor activity upon cocaine administration.

Thus, the aforementioned report supports that cocaine 
must actually interact with and block DAT in order to elicit its effects of reward and ultimately increase DA in the nucleus accumbens. This is supported by voltammetry experiments ${ }^{86,87)}$ and gives valuable in vivo data to support the emerging cocaine-DAT interaction theory.

\section{Physiological Interactions and Regulation of Cocaine and DAT}

Even though the DAT can be (and has been) pharmacologically manipulated, the brain also has unique DAT regulatory mechanisms. If cocaine were to get into the brain, its in vivo interactions with DAT would have effects at the molecular, cellular, and behavioral levels. Thus, signaling mechanisms that involve DAT and/or cocaine in some way can be studied from multiple perspectives, some of which will be examined in this section.

There is significant debate as to whether cocaine administration decreases, ${ }^{88-94)}$ increases, ${ }^{95-101)}$ or does not affect $^{102-108)}$ DAT-cocaine or DAT-cocaine analog binding sites. In addition, Letchworth et al. ${ }^{109)}$ reported a decrease in DAT mRNA levels in the substantia nigra and the VTA but no change in DAT protein levels in the striatum. This all indicates that there are many differences among individual reports. For example, many different dopaminergic areas of the brain are examined, such as the nucleus accumbens, VTA, striatum, substantia nigra, and basal ganglia. ${ }^{110)}$ Moreover, different cocaine levels, cocaine analogs, ${ }^{111)}$ intervals/frequency of cocaine exposure, methods of measurement (autoradiography, in situ hybridization, polymerase chain reaction, Western blot, immunohistochemistry, etc.), and even methods of administration $^{106)}$ could all be possible explanations of inconsistent and debatable results.

Furthermore, many decreases in DAT binding sites for cocaine or analogs were caused by withdrawal from cocaine, ${ }^{88,91,94)}$ insinuating that the physiological DAT-cocaine interaction mechanism and DAT binding sites may be regulated by how much cocaine (or analog) is available to a given DAT protein.

One thing that is more agreed upon is that the cocaine-DAT binding mechanisms are indeed complex and may be quite plastic and dynamic in their abilities to quickly sense increased cocaine exposure and respond in a prompt manner (by changing the binding affinities and/or sites). This may partly underlie the powerful addiction felt by cocaine addicts.

If indeed the cocaine-DAT binding does fluctuate between increased, decreased, and constant when they are exposed to cocaine (or an analog), there are a few theories that may explain the seemingly bewildering results. DAT could potentially sensitize or desensitize in the presence of cocaine, which would explain the increasing or decreasing binding. This may be similar to sensitization after exposure to morphine, leading to a rewarding effect. ${ }^{112)}$ In fact, cocaine has long been shown to be involved with sensitization in the central nervous system, ${ }^{113)}$ on DA receptors, ${ }^{114,115)}$ and even on N-methyl-D-aspartate receptors. ${ }^{116)}$ Conversely, reports of cocaine-induced desensitization are not as abundant. ${ }^{117)}$

Despite the lack of these desensitization studies, a theory that may explain a decrease in DAT-cocaine binding after cocaine exposure relates to homeostasis. ${ }^{92)}$ In response to cocaine exposure, increased amounts of extracellular DA are present. This causes a homeostatic mechanism to turn on that results in more DA being shuttled back into the neuron(s). Theoretically, that mechanism could be decreased binding of cocaine and DAT; if true, it would explain why less binding of the two would cause a homeostatic response to decrease extracellular DA after an increase.

Elucidating why the aforementioned studies ${ }^{102-108)}$ reported no change in DAT-cocaine binding is a much more difficult task. Perhaps the results were due to different regions of the brain tested. Different dopaminergic regions of the brain may need different levels of cocaine or different frequencies of cocaine exposure in order to elicit a given effect, and if the amount/frequency of cocaine administered is lower than this "threshold," then no significant difference in DAT-cocaine binding will be recorded. Thus, it is possible that some methodological issues cause the insignificant change in DAT-cocaine interaction after cocaine administration.

Having discussed the DAT-cocaine binding being affected by cocaine, another aspect of the DAT-cocaine interaction is the controlling of DAT gene expression by cocaine administration. It is known that cocaine increases DAT expression in dopaminergic areas of the brain, ${ }^{118-121)}$ and well-known that abstinence of cocaine intake for a prolonged period of time decreases DAT levels. ${ }^{90,110,122-126)}$ Cocaine is also involved with DAT trafficking to the plasma membrane. ${ }^{47,119,127)}$ Thus, similar to DAT-cocaine binding, DAT gene expression is a constantly changing system that is able to respond directly to cocaine levels and adjust DAT levels.

Cocaine can also participate in signaling, resulting in maintenance of DAT levels, further adding credence to its role of increasing DAT expression. It is known that PKC phosphorylates DAT, downregulates its activity, and caus- 
es it to be endocytosed. ${ }^{47,49)}$ The PKC activator phorbol-12-myristate-13-acetate (PMA) also increases DAT phosphorylation and downregulation. ${ }^{39,128)}$ However, PMA-mediated PKC phosphorylation is known to be blocked in the striatum by cocaine. ${ }^{129)}$ As a result, cocaine can also exert indirect effects to keep the level of DAT high. These studies collectively suggest that cocaine stops natural PKC-based regulation of DAT and offers a mechanistic reason as to why sustained levels of DAT are seen in cocaine abusers. It remains to be seen how and in what capacity cocaine affects PKC in other ways (and by other mechanisms) that are unrelated to DAT. That cocaine changes the dopaminergic system in so many ways and mechanisms is better supported. This prompts the necessity for more investigation in order to find out in what other ways, in addition to what has been shown, does cocaine exert its powerful addictive effect.

The DAT-cocaine binding and cocaine-induced DAT gene expression may collectively be regulated by proteins that regulate DAT, thus adding another level of regulation to DAT. DAT is known to be regulated by many proteins, found through many different methods, ${ }^{130)}$ such as PICK-1, ${ }^{131)}$ Hic-5 ${ }^{132)}$ SNAP-25 (G. Torres, unpublished observations), synuclein, ${ }^{133)}$ the $\mathrm{DA} \mathrm{D}_{2}$ receptor, ${ }^{134,135)}$ and others. ${ }^{49,136)}$ Despite the growing number of DAT-interacting proteins that are being found, discovery of more will certainly bring new insights into their roles in disorders of the dopaminergic system, as well as their functions in regulating the cocaine-DAT interaction.

\section{Effects of the Cocaine-DAT Interaction}

DAT is known to be involved in attention-deficit (hyperactivity) disorder and PD; ${ }^{137,138)}$ in fact, DAT inhibitors have been shown to alleviate the symptoms of PD in monkeys. ${ }^{139)}$ DAT knockout mice have abnormal social interactions, ${ }^{140)}$ diminished olfactory discrimination, ${ }^{141)}$ and even changes in immune response. ${ }^{142)}$

Cocaine's powerful effects can be seen firsthand in cocaine addicts. Those who abuse cocaine have been shown to sustain their levels of DAT; aging naturally reduces the levels of DAT, but this is not the case in cocaine abusers. ${ }^{143)}$ Furthermore, cocaine has effects all over the body, and thus finding a therapy to reverse the effects is considered a very difficult task. ${ }^{144)}$ This further augments the claim that the interaction between DAT and cocaine is strong enough to create major long-lasting changes in the entire body.

Despite the fact that it is not known how exactly cocaine exerts its addiction, whether it is by sensitization of re- ceptors $^{114,115)}$ and/or causing an increase in DAT gene expression, ${ }^{118-121)}$ both would explain an addict's incessant craving for cocaine. In order to be sure about what really goes on in the cocaine abuser's brain, further studies must be done in order to elucidate 1) more effects of cocaine on the DAT, 2) how that interaction leads to addiction, and 3) the mechanisms associated with the interaction.

It is important to note that the cocaine-DAT interaction is mutually dependent; that is, the interaction would be far from functional if cocaine or DAT were not present. In the brain of a cocaine addict, cocaine and DAT would be coming in contact with each other regularly; if the cocaine supply would be cut, the addict would experience strong withdrawal symptoms. Thus, the effect of cocaine removal on DAT can be readily seen. However, it is interesting to ponder the effects if DAT was removed; this was in fact done in reports with DAT knockout mice. ${ }^{81,145)}$ These mice were reported to have been unresponsive to cocaine or amphetamine and showed neither DA release nor hyperlocomotion upon administration with either of the two psychostimulants. Despite the reported results, the studies have been disputed. For instance, since cocaine acts on NET and SERT, some degree of responsiveness to cocaine and/or hyperlocomotion would be expected. ${ }^{75-79)}$ This indicates that without DAT, cocaine cannot exert its full effects (even when considering compensation by other monoamine transporters); a functional and strong cocaine-DAT interaction must involve both partners.

The ramifications of having such a mutual interaction are that if one part is altered in even the slightest way, the whole interaction falls apart. This can be taken advantage of; if the DAT protein was mutated at a strategic place, cocaine may not bind to it and cocaine self-administration may stop. ${ }^{86)}$ However, perhaps a more feasible option to use, especially for real-world applications, is occupying DAT with a ligand that is of higher affinity than cocaine. ${ }^{146-148)}$ This was in fact done with the use of (-)2 $\beta$-propanoyl-3 $\beta$-(4-tolyl)-tropane (PTT), which has a very high affinity for DAT. ${ }^{148)}$ Rhesus monkeys treated with PTT showed a decrease in cocaine intake, suggesting that the presence of PTT induced the lack of cocaine intake in the monkey. Thus, the DAT-cocaine interaction and ways to modify the interaction have generated much interest in pharmacology and those attempting to make treatments for cocaine abuse.

Another major effect of the strong cocaine-DAT interaction is its effect on behavior. Gulley et al. ${ }^{149)}$ underscore the profound impact that even one exposure to cocaine can have on behavior. The transduction from drug intake to 
behavioral changes may be explained by cocaine increasing the DAT numbers on the cell surface. ${ }^{47,119-122,128)}$ The different numbers of DAT proteins on the cell surface in turn results in behavioral changes. ${ }^{150)}$ Accordingly, the behavioral changes may be more pronounced if more cocaine is administered and more DATs are inserted into the membrane.

Because the cocaine-DAT system is thought to work in this manner, therapy for cocaine abusers may lie within stopping cocaine-induced DAT transcription (and/or translation). If this is done, there may be lower levels of DAT proteins on the cell surface. Because there are less DAT proteins to begin with, less have a chance to be occupied with cocaine. Less DAT occupation would result in less of a reported "high", ${ }^{151)}$ and may lessen the molecular changes in the brain as well as the behavioral changes in the addict.

The impact that the cocaine-DAT interaction has is critical for normal function, yet can be readily disturbed by psychostimulants. The sequence of events that occur in the neuron and brain, from cocaine exposure to behavioral effects, have great effects on the function of the DAT, synaptosome, neuron, and even the particular dopaminergic region of the brain itself. Thus, developing a solution to alleviate behavioral (and even neuronal) effects may be quite intricate and challenging; more research will be essential to elucidate the effects of the cocaine-DAT interaction at the molecular, cellular, and behavioral levels.

\section{Alternative Mechanisms for Cocaine Action}

An intriguing study ${ }^{152)}$ illustrated an alternative mechanism by which cocaine may act on dopaminergic neurons. The group used cyclic voltammetry to record DA release from anesthetized murine caudate-putamen while stimulated in the presence or absence of cocaine. While cocaine expectedly resulted in more DA measured, the result was different in another murine model used. Synapsin-knockout (SKO) mice lack synapsins I/II/III, the proteins that are responsible for holding vesicles in the storage region of an axon terminal. When stimulation was done with cocaine on SKO mice, the DA release was found to be decreased. This result suggested the role of cocaine in mobilizing the dopaminergic vesicles that are in the storage region (normally anchored by synapsins) of the synaptosome.

Another set of experiments in the same report further implicated the storage region as interacting with cocaine. By adding $\alpha$-methyl-p-tyrosine, a DA synthesis blocker, the readily-releasable pool of vesicles was soon eliminated and DA efflux decreased. However, recovery of DA efflux was seen upon cocaine administration, presumably because of cocaine's action on mobilizing the storage region's vesicles. Furthermore, this effect was not seen in SKO mice; even after cocaine addition, the DA efflux remained low, thus further indicating the role that cocaine plays in storage vesicle-mediated DA efflux.

According to the proposed mechanism, cocaine was able to release the dopaminergic vesicles that are in the storage region of the synaptosome. This would mean that cocaine acted to stimulate DA release and then also maintain extracellular DA by blocking DAT with a high affinity. Not only would this interaction explain cocaine's addiction, but also its ability to stimulate under many conditions. Because cocaine's action was independent of the readily-releasable pool, cocaine could exert its stimulatory effect even if a dopaminergic neuron has been heavily stimulated (and has lost many of its readily-releasable vesicles). Thus, cocaine may be more versatile than originally thought, being able to affect the dopaminergic system even when it has been exhausted of its readily-releasable vesicles by intense stimulation.

If indeed cocaine interacts with DAT and mobilizes the storage pool, the impact of cocaine on dopaminergic neurons must be altered yet again to consider another level of cocaine potency. However, many questions left to be answered, such as whether cocaine affects only dopaminergic or catecholaminergic neurons in this manner, or how cocaine can get into the synaptosome in the first place.

\section{CONCLUSIONS AND FUTURE CONSIDERATIONS}

There is much exciting research going on with regards to further characterizing the relationship of cocaine and the DAT, with clinical consequences regarding psychiatric disease and drug addiction. These are often seen as the most paralyzing and debilitating conditions and cost health care systems exorbitant sums of money every year. The future brings promise; accordingly, this review highlights the classic studies of the 1990s and 2000s that helped build our knowledge base on this topic to what it is today, which in turn can lead to tomorrow's therapies.

Cocaine and the DAT form a strong interaction that translates into strong effects in the synaptic cleft, brain, and behavior. Disorders of dopaminergic systems such as PD and cocaine addiction will potentially benefit from more research pertaining to the cocaine-DAT interaction. There may be other significant interactions that cocaine and/or DAT play a role in that may be of some interest, not 
only to dopaminergic system disorders. Indeed, an aim of the future will be to get closer to determining all the proteins that DAT interacts with, and how each interaction is physiologically and functionally relevant to dopaminergic neurotransmission and homeostasis, behavior, addiction, and disorders of the dopaminergic system.

Venton et al. ${ }^{152)}$ is an excellent example of the fact that the cocaine-DAT interaction theory is constantly being revised and re-revised. Similar to this study, more research on cocaine's interactions with dopaminergic neurons in general could highlight the total and profound impact that cocaine has; another primary objective of the future will be to come closer to finding the full effects of cocaine on the DAT, dopaminergic neurons, the brain in general, and psychological behavior.

\section{Acknowledgments}

The author acknowledges Dr. Gonzalo Torres for his review of the manuscript.

\section{REFERENCES}

1. Mohr E, Mendis T, Grimes JD. Late cognitive changes in Parkinson's disease with an emphasis on dementia. Adv Neurol 1995;65:97-113.

2. Han $\mathrm{DD}, \mathrm{Gu} \mathrm{HH}$. Comparison of the monoamine transporters from human and mouse in their sensitivities to psychostimulant drugs. BMC Pharmacol 2006;6:6.

3. Reith ME, Meisler BE, Sershen H, Lajtha A. Structural requirements for cocaine congeners to interact with dopamine and serotonin uptake sites in mouse brain and to induce stereotyped behavior. Biochem Pharmacol 1986:35:1123-1129.

4. Madras BK, Fahey MA, Bergman J, Canfield DR, Spealman RD. Effects of cocaine and related drugs in nonhuman primates. I. [3H]cocaine binding sites in caudate-putamen. J Pharmacol Exp Ther 1989;251:131-141.

5. Rothman RB, Baumann MH, Dersch CM, Romero DV, Rice KC, Carroll FI, et al. Amphetamine-type central nervous system stimulants release norepinephrine more potently than they release dopamine and serotonin. Synapse 2001;39:32-41.

6. Wang Z, Ordway GA, Woolverton W. Effects of cocaine on monoamine uptake as measured ex vivo. Neurosci Lett 2007;413:191-195.

7. Ritz MC, Lamb RJ, Goldberg SR, Kuhar MJ. Cocaine receptors on dopamine transporters are related to selfadministration of cocaine. Science 1987;237:1219-1223.

8. Jones SR, Garris PA, Wightman RM. Different effects of cocaine and nomifensine on dopamine uptake in the caudate-putamen and nucleus accumbens. J Pharmacol Exp Ther 1995;274:396-403.

9. Davis M. Cocaine: excitatory effects on sensorimotor reactivity measured with acoustic startle. Psychopharmacology (Berl) 1985;86:31-36.

10. Kuhar MJ, Ritz MC, Boja JW. The dopamine hypothesis of the reinforcing properties of cocaine. Trends Neurosci 1991; 14:299-302.

11. Barr GA, Rossi G. Conditioned place preference from ventral tegmental injection of morphine in neonatal rats. Brain Res Dev Brain Res 1992;66:133-136.

12. Fiorino DF, Coury A, Fibiger HC, Phillips AG. Electrical stimulation of reward sites in the ventral tegmental area increases dopamine transmission in the nucleus accumbens of the rat. Behav Brain Res 1993;55:131-141.

13. Ikemoto S, Wise RA. Rewarding effects of the cholinergic agents carbachol and neostigmine in the posterior ventral tegmental area. J Neurosci 2002;22:9895-9904.

14. Childress AR, Mozley PD, McElgin W, Fitzgerald J, Reivich M, O'Brien CP. Limbic activation during cueinduced cocaine craving. Am J Psychiatry 1999;156:11-18.

15. Hall FS, Sora I, Drgonova J, Li XF, Goeb M, Uhl GR. Molecular mechanisms underlying the rewarding effects of cocaine. Ann N Y Acad Sci 2004;1025:47-56.

16. Hastrup H, Karlin A, Javitch JA. Symmetrical dimer of the human dopamine transporter revealed by cross-linking Cys-306 at the extracellular end of the sixth transmembrane segment. Proc Natl Acad Sci U S A 2001;98:1005510060.

17. Torres GE, Carneiro A, Seamans K, Fiorentini C, Sweeney A, Yao WD, et al. Oligomerization and trafficking of the human dopamine transporter. Mutational analysis identifies critical domains important for the functional expression of the transporter. J Biol Chem 2003;278:2731-2739.

18. Hastrup H, Sen N, Javitch JA. The human dopamine transporter forms a tetramer in the plasma membrane: cross-linking of a cysteine in the fourth transmembrane segment is sensitive to cocaine analogs. J Biol Chem 2003; $278: 45045-45048$.

19. Giros B, Wang YM, Suter S, McLeskey SB, Pifl C, Caron MG. Delineation of discrete domains for substrate, cocaine, and tricyclic antidepressant interactions using chimeric dopamine-norepinephrine transporters. J Biol Chem 1994;269:15985-15988.

20. Buck KJ, Amara SG. Chimeric dopamine-norepinephrine transporters delineate structural domains influencing selectivity for catecholamines and 1-methyl-4-phenylpyridinium. Proc Natl Acad Sci U S A 1994;91:12584-12588.

21. Buck KJ, Amara SG. Structural domains of catecholamine transporter chimeras involved in selective inhibition by antidepressants and psychomotor stimulants. Mol Pharmacol 1995;48:1030-1037.

22. Beuming T, Kniazeff J, Bergmann ML, Shi L, Gracia L, Raniszewska $\mathrm{K}$, et al. The binding sites for cocaine and dopamine in the dopamine transporter overlap. Nat Neurosci 2008;11:780-789.

23. Chen N, Reith ME. Structure and function of the dopamine transporter. Eur J Pharmacol 2000;405:329-339.

24. Giros B, el Mestikawy S, Godinot N, Zheng K, Han H, Yang-Feng $\mathrm{T}$, et al. Cloning, pharmacological characterization, and chromosome assignment of the human dopamine transporter. Mol Pharmacol 1992;42:383-390.

25. Javitch JA, D'Amato RJ, Strittmatter SM, Snyder SH. Parkinsonism-inducing neurotoxin, N-methyl-4-phenyl-1,2,3,6tetrahydropyridine: uptake of the metabolite N-methyl-4phenylpyridine by dopamine neurons explains selective toxicity. Proc Natl Acad Sci US A 1985;82:2173-2177.

26. Chiba K, Trevor AJ, Castagnoli N Jr. Active uptake of $M P P+$, a metabolite of MPTP, by brain synaptosomes. Biochem Biophys Res Commun 1985;128:1228-1232.

27. Willoughby J, Cowburn RF, Hardy JA, Glover V, Sandler M. 1-Methyl-4-phenylpyridinium uptake by human and rat striatal synaptosomes. J Neurochem 1989;52:627-631.

28. Tipton KF, Singer TP. Advances in our understanding of 
the mechanisms of the neurotoxicity of MPTP and related compounds. J Neurochem 1993;61:1191-1206.

29. Storch A, Ludolph AC, Schwarz J. Dopamine transporter: involvement in selective dopaminergic neurotoxicity and degeneration. J Neural Transm 2004;111:1267-1286.

30. Di Matteo V, Benigno A, Pierucci M, Giuliano DA, Crescimanno G, Esposito E, et al. 7-nitroindazole protects striatal dopaminergic neurons against MPP+-induced degeneration: an in vivo microdialysis study. Ann $N Y$ Acad Sci 2006;1089:462-471.

31. Gainetdinov RR, Fumagalli F, Jones SR, Caron MG. Dopamine transporter is required for in vivo MPTP neurotoxicity: evidence from mice lacking the transporter. J Neurochem 1997;69:1322-1325.

32. Mayer RA, Kindt MV, Heikkila RE. Prevention of the nigrostriatal toxicity of 1-methyl-4-phenyl-1,2,3,6-tetrahydropyridine by inhibitors of 3,4-dihydroxyphenylethylamine transport. J Neurochem 1986;47:1073-1079.

33. Lin Z, Itokawa M, Uhl GR. Dopamine transporter proline mutations influence dopamine uptake, cocaine analog recognition, and expression. FASEB J 2000;14:715-728.

34. Dar DE, Metzger TG, Vandenbergh DJ, Uhl GR. Dopamine uptake and cocaine binding mechanisms: the involvement of charged amino acids from the transmembrane domains of the human dopamine transporter. Eur $J$ Pharmacol 2006;538:43-47.

35. Kitayama S, Shimada S, Xu H, Markham L, Donovan DM, Uhl GR. Dopamine transporter site-directed mutations differentially alter substrate transport and cocaine binding. Proc Natl Acad Sci U S A 1992;89:7782-7785.

36. Kitayama S, Wang JB, Uhl GR. Dopamine transporter mutants selectively enhance MPP+ transport. Synapse 1993; 15:58-62.

37. Pifl C, Agneter E, Drobny H, Reither H, Singer EA. Induction by low $\mathrm{Na}+$ or $\mathrm{Cl}-$ of cocaine sensitive carrier-mediated efflux of amines from cells transfected with the cloned human catecholamine transporters. $\mathrm{Br} J$ Pharmacol 1997;121:205-212.

38. Uhl GR. Dopamine transporter: basic science and human variation of a key molecule for dopaminergic function, locomotion, and parkinsonism. Mov Disord 2003;18 Suppl 7:S71-S80

39. Copeland BJ, Vogelsberg V, Neff NH, Hadjiconstantinou M. Protein kinase $C$ activators decrease dopamine uptake into striatal synaptosomes. J Pharmacol Exp Ther 1996; 277:1527-1532.

40. Huff RA, Vaughan RA, Kuhar MJ, Uhl GR. Phorbol esters increase dopamine transporter phosphorylation and decrease transport Vmax. J Neurochem 1997;68:225-232.

41. Vaughan RA, Huff RA, Uhl GR, Kuhar MJ. Protein kinase $C$-mediated phosphorylation and functional regulation of dopamine transporters in striatal synaptosomes. J Biol Chem 1997;272:15541-15546.

42. Foster JD, Pananusorn B, Vaughan RA. Dopamine transporters are phosphorylated on N-terminal serines in rat striatum. J Biol Chem 2002;277:25178-25186.

43. Lin Z, Zhang PW, Zhu X, Melgari JM, Huff R, Spieldoch $\mathrm{RL}$, et al. Phosphatidylinositol 3-kinase, protein kinase C, and MEK1/2 kinase regulation of dopamine transporters (DAT) require $N$-terminal DAT phosphoacceptor sites. $J$ Biol Chem 2003;278:20162-20170.

44. Corey JL, Davidson N, Lester HA, Brecha N, Quick MW. Protein kinase $C$ modulates the activity of a cloned gamma-aminobutyric acid transporter expressed in Xenopus oocytes via regulated subcellular redistribution of the transporter. J Biol Chem 1994;269:14759-14767.

45. Qian Y, Galli A, Ramamoorthy S, Risso S, DeFelice LJ, Blakely RD. Protein kinase $C$ activation regulates human serotonin transporters in HEK-293 cells via altered cell surface expression. J Neurosci 1997;17:45-57.

46. Ramamoorthy S, Blakely RD. Phosphorylation and sequestration of serotonin transporters differentially modulated by psychostimulants. Science 1999;285:763-766.

47. Melikian HE, Buckley KM. Membrane trafficking regulates the activity of the human dopamine transporter. $J$ Neurosci 1999;19:7699-7710.

48. Daniels GM, Amara SG. Regulated trafficking of the human dopamine transporter. Clathrin-mediated internalization and lysosomal degradation in response to phorbol esters. J Biol Chem 1999;274:35794-35801.

49. Doolen S, Zahniser NR. Conventional protein kinase $C$ isoforms regulate human dopamine transporter activity in Xenopus oocytes. FEBS Lett 2002;516:187-190.

50. Torres GE. The dopamine transporter proteome. J Neurochem 2006;97 Suppl 1:3-10.

51. Volkow ND, Wang GJ, Fowler JS, Fischman M, Foltin R, Abumrad NN, et al. Methylphenidate and cocaine have a similar in vivo potency to block dopamine transporters in the human brain. Life Sci 1999;65:PL7-PL12.

52. Rothman RB, Carroll FI, Morales M, Rowley DL, Rice $\mathrm{KC}$, Dersch CM, et al. Studies of the biogenic amine transporters. 10. Characterization of a novel cocaine binding site in brain membranes prepared from dopamine transporter knockout mice. Synapse 2002;44:94-105.

53. Boja JW, Mitchell WM, Patel A, Kopajtic TA, Carroll FI, Lewin AH, et al. High-affinity binding of [125I]RTI-55 to dopamine and serotonin transporters in rat brain. Synapse 1992;12:27-36.

54. Carroll FI, Abraham P, Lewin AH, Parham KA, Boja JW, Kuhar M. Isopropyl and phenyl esters of 3 beta-(4substituted phenyl)tropan-2 beta-carboxylic acids. Potent and selective compounds for the dopamine transporter. $J$ Med Chem 1992;35:2497-2500.

55. Rothman RB, Cadet JL, Akunne HC, Silverthorn ML, Baumann MH, Carroll FI, et al. Studies of the biogenic amine transporters. IV. Demonstration of a multiplicity of binding sites in rat caudate membranes for the cocaine analog [125I]RTI-55. J Pharmacol Exp Ther 1994;270: 296-309.

56. Staley JK, Basile M, Flynn DD, Mash DC. Visualizing dopamine and serotonin transporters in the human brain with the potent cocaine analogue [125I]RTI-55: in vitro binding and autoradiographic characterization. J Neurochem 1994;62:549-556.

57. Rothman RB, Baumann MH. Monoamine transporters and psychostimulant drugs. Eur J Pharmacol 2003;479:23-40.

58. Reith ME, Coffey LL. Cationic and anionic requirements for the binding of 2 beta-carbomethoxy-3 beta-(4-fluorophenyl)[3H] tropane to the dopamine uptake carrier. J Neurochem 1993;61:167-177.

59. Chen N, Zhen J, Reith ME. Mutation of Trp 84 and Asp313 of the dopamine transporter reveals similar mode of binding interaction for GBR12909 and benztropine as opposed to cocaine. J Neurochem 2004;89:853-864.

60. Vaughan RA, Sakrikar DS, Parnas ML, Adkins S, Foster JD, Duval RA, et al. Localization of cocaine analog [125I]RTI 82 irreversible binding to transmembrane domain 6 of the dopamine transporter. J Biol Chem 2007;282:8915-8925.

61. Ravna AW, Sylte I, Dahl SG. Molecular model of the neural dopamine transporter. J Comput Aided Mol Des 
2003;17:367-382.

62. Volz TJ, Schenk JO. A comprehensive atlas of the topography of functional groups of the dopamine transporter. Synapse 2005;58:72-94.

63. Surratt CK, Ukairo OT, Ramanujapuram S. Recognition of psychostimulants, antidepressants, and other inhibitors of synaptic neurotransmitter uptake by the plasma membrane monoamine transporters. AAPS J 2005;7:E739-E751.

64. Wang W, Sonders MS, Ukairo OT, Scott H, Kloetzel MK, Surratt CK. Dissociation of high-affinity cocaine analog binding and dopamine uptake inhibition at the dopamine transporter. Mol Pharmacol 2003;64:430-439.

65. Chen N, Vaughan RA, Reith ME. The role of conserved tryptophan and acidic residues in the human dopamine transporter as characterized by site-directed mutagenesis. $J$ Neurochem 2001;77:1116-1127.

66. Kimmel HL, O'Connor JA, Carroll FI, Howell LL. Faster onset and dopamine transporter selectivity predict stimulant and reinforcing effects of cocaine analogs in squirrel monkeys. Pharmacol Biochem Behav 2007;86:45-54.

67. Surratt CK, Wang JB, Yuhasz S, Amzel M, Kwon HM, Handler JS, et al. Sodium- and chloride-dependent transporters in brain, kidney, and gut: lessons from complementary DNA cloning and structure-function studies. Curr Opin Nephrol Hypertens 1993;2:744-760.

68. Loland CJ, Grånäs C, Javitch JA, Gether U. Identification of intracellular residues in the dopamine transporter critical for regulation of transporter conformation and cocaine binding. J Biol Chem 2004;279:3228-3238.

69. Lin Z, Uhl GR. Dopamine transporter mutants with cocaine resistance and normal dopamine uptake provide targets for cocaine antagonism. Mol Pharmacol 2002;61: 885-891.

70. Kitayama S, Morita K, Dohi T, Wang JB, Davis SC, Uhl GR. Dissection of dopamine and cocaine binding sites on the rat dopamine transporter expressed in COS cells. Ann N Y Acad Sci 1996;801:388-393.

71. Chen JG, Sachpatzidis A, Rudnick G. The third transmembrane domain of the serotonin transporter contains residues associated with substrate and cocaine binding. $J$ Biol Chem 1997;272:28321-28327.

72. Mitsuhata C, Kitayama S, Morita K, Vandenbergh D, Uhl GR, Dohi T. Tyrosine-533 of rat dopamine transporter: involvement in interactions with 1-methyl-4-phenylpyridinium and cocaine. Brain Res Mol Brain Res 1998;56:84-88.

73. Lin Z, Wang W, Kopajtic T, Revay RS, Uhl GR. Dopamine transporter: transmembrane phenylalanine mutations can selectively influence dopamine uptake and cocaine analog recognition. Mol Pharmacol 1999;56:434-447.

74. Lee SH, Chang MY, Lee KH, Park BS, Lee YS, Chin HR, et al. Importance of valine at position 152 for the substrate transport and 2beta-carbomethoxy-3beta-(4-fluorophenyl) tropane binding of dopamine transporter. Mol Pharmacol 2000;57:883-889.

75. Rocha BA, Fumagalli F, Gainetdinov RR, Jones SR, Ator $\mathrm{R}$, Giros B, et al. Cocaine self-administration in dopaminetransporter knockout mice. Nat Neurosci 1998;1:132-137.

76. Carboni E, Spielewoy C, Vacca C, Nosten-Bertrand M, Giros B, Di Chiara G. Cocaine and amphetamine increase extracellular dopamine in the nucleus accumbens of mice lacking the dopamine transporter gene. J Neurosci 2001;21: RC141:1-4.

77. Sora I, Hall FS, Andrews AM, Itokawa M, Li XF, Wei HB, et al. Molecular mechanisms of cocaine reward: combined dopamine and serotonin transporter knockouts eliminate cocaine place preference. Proc Natl Acad Sci USA 2001;98:5300-5305.

78. Mateo Y, Budygin EA, John CE, Jones SR. Role of serotonin in cocaine effects in mice with reduced dopamine transporter function. Proc Natl Acad Sci $U S A$ 2004; 101:372-377.

79. Medvedev IO, Gainetdinov RR, Sotnikova TD, Bohn LM, Caron MG, Dykstra LA. Characterization of conditioned place preference to cocaine in congenic dopamine transporter knockout female mice. Psychopharmacology (Berl) 2005; 180:408-413.

80. Jones SR, Gainetdinov RR, Hu XT, Cooper DC, Wightman $\mathrm{RM}$, White FJ, et al. Loss of autoreceptor functions in mice lacking the dopamine transporter. Nat Neurosci 1999;2: 649-655.

81. Giros B, Jaber M, Jones SR, Wightman RM, Caron MG. Hyperlocomotion and indifference to cocaine and amphetamine in mice lacking the dopamine transporter. Nature 1996;379:606-612.

82. Caine SB. Cocaine abuse: hard knocks for the dopamine hypothesis? Nat Neurosci 1998;1:90-92.

83. Uhl G, Hall FS, Sora I. Cocaine, reward, movement and monoamine transporters. Mol Psychiatry 2002;7:21-26.

84. Rocha BA. Stimulant and reinforcing effects of cocaine in monoamine transporter knockout mice. Eur J Pharmacol 2003;479:107-115.

85. Chen R, Tilley MR, Wei H, Zhou F, Zhou FM, Ching S, et al. Abolished cocaine reward in mice with a cocaineinsensitive dopamine transporter. Proc Natl Acad Sci U S A 2006; 103:9333-9338.

86. Wu Q, Reith ME, Kuhar MJ, Carroll FI, Garris PA. Preferential increases in nucleus accumbens dopamine after systemic cocaine administration are caused by unique characteristics of dopamine neurotransmission. $J$ Neurosci 2001;21:6338-6347.

87. Greco PG, Garris PA. In vivo interaction of cocaine with the dopamine transporter as measured by voltammetry. Eur $J$ Pharmacol 2003;479:117-125.

88. Sharpe LG, Pilotte NS, Mitchell WM, De Souza EB. Withdrawal of repeated cocaine decreases autoradiographic [3H]mazindol-labelling of dopamine transporter in rat nucleus accumbens. Eur J Pharmacol 1991;203:141-144.

89. Farfel GM, Kleven MS, Woolverton WL, Seiden LS, Perry BD. Effects of repeated injections of cocaine on catecholamine receptor binding sites, dopamine transporter binding sites and behavior in rhesus monkey. Brain Res 1992;578:235243.

90. Byrnes JJ, Pritchard GA, Koff JM, Miller LG. Prenatal cocaine exposure: decreased sensitization to cocaine and decreased striatal dopamine transporter binding in offspring. Neuropharmacology 1993;32:721-723.

91. Pilotte NS, Sharpe LG, Kuhar MJ. Withdrawal of repeated intravenous infusions of cocaine persistently reduces binding to dopamine transporters in the nucleus accumbens of Lewis rats. $J$ Pharmacol Exp Ther 1994;269:963-969.

92. Wilson JM, Nobrega JN, Carroll ME, Niznik HB, Shannak $\mathrm{K}$, Lac ST, et al. Heterogeneous subregional binding patterns of $3 H$-WIN 35,428 and $3 H-G B R \quad 12,935$ are differentially regulated by chronic cocaine self-administration. J Neurosci 1994;14:2966-2979.

93. Boulay D, Duterte-Boucher D, Leroux-Nicollet I, Naudon $\mathrm{L}$, Costentin J. Locomotor sensitization and decrease in [3H]mazindol binding to the dopamine transporter in the nucleus accumbens are delayed after chronic treatments by GBR12783 or cocaine. J Pharmacol Exp Ther 1996;278: 
330-337.

94. Pilotte NS, Sharpe LG, Rountree SD, Kuhar MJ. Cocaine withdrawal reduces dopamine transporter binding in the shell of the nucleus accumbens. Synapse 1996;22:87-92.

95. Alburges ME, Narang N, Wamsley JK. Alterations in the dopaminergic receptor system after chronic administration of cocaine. Synapse 1993;14:314-323.

96. Little KY, Kirkman JA, Carroll FI, Clark TB, Duncan GE. Cocaine use increases [3H]WIN 35428 binding sites in human striatum. Brain Res 1993;628:17-25.

97. Staley JK, Hearn WL, Ruttenber AJ, Wetli CV, Mash DC. High affinity cocaine recognition sites on the dopamine transporter are elevated in fatal cocaine overdose victims. J Pharmacol Exp Ther 1994;271:1678-1685.

98. Hitri A, Little KY, Ellinwood EH Jr. Effect of cocaine on dopamine transporter receptors depends on routes of chronic cocaine administration. Neuropsychopharmacology 1996; 14:205-210.

99. Little KY, McLaughlin DP, Zhang L, McFinton PR, Dalack $\mathrm{GW}$, Cook EH Jr, et al. Brain dopamine transporter messenger RNA and binding sites in cocaine users: a postmortem study. Arch Gen Psychiatry 1998;55:793-799.

100. Malison RT, Best SE, van Dyck CH, McCance EF, Wallace EA, Laruelle M, et al. Elevated striatal dopamine transporters during acute cocaine abstinence as measured by [123I] beta-CIT SPECT. Am J Psychiatry 1998;155: 832-834.

101. Little KY, Zhang L, Desmond T, Frey KA, Dalack GW, Cassin BJ. Striatal dopaminergic abnormalities in human cocaine users. Am J Psychiatry 1999;156:238-245.

102. Allard P, Eriksson K, Ross SB, Marcusson JO. Unaltered [3H]GBR-12935 binding after chronic treatment with dopamine active drugs. Psychopharmacology (Berl) 1990; 102:291-294.

103. Kula NS, Baldessarini RJ. Lack of increase in dopamine transporter binding or function in rat brain tissue after treatment with blockers of neuronal uptake of dopamine. Neuropharmacology 1991;30:89-92.

104. Benmansour S, Tejani-Butt SM, Hauptmann M, Brunswick DJ. Lack of effect of high-dose cocaine on monoamine uptake sites in rat brain measured by quantitative autoradiography. Psychopharmacology (Berl) 1992;106: 459-462.

105. Cass WA, Gerhardt GA, Gillespie K, Curella P, Mayfield $\mathrm{RD}$, Zahniser NR. Reduced clearance of exogenous dopamine in rat nucleus accumbens, but not in dorsal striatum, following cocaine challenge in rats withdrawn from repeated cocaine administration. J Neurochem 1993;61:273-283.

106. Wilson JM, Nobrega JN, Corrigall WA, Coen KM, Shannak K, Kish SJ. Amygdala dopamine levels are markedly elevated after self- but not passive-administration of cocaine. Brain Res 1994;668:39-45.

107. Wilson JM, Levey AI, Bergeron C, Kalasinsky K, Ang L, Peretti F, et al. Striatal dopamine, dopamine transporter, and vesicular monoamine transporter in chronic cocaine users. Ann Neurol 1996;40:428-439.

108. Kunko PM, Loeloff RJ, Izenwasser S. Chronic administration of the selective dopamine uptake inhibitor $G B R$ 12,909, but not cocaine, produces marked decreases in dopamine transporter density. Naunyn Schmiedebergs Arch Pharmacol 1997;356:562-569.

109. Letchworth SR, Sexton T, Childers SR, Vrana KE, Vaughan RA, Davies HM, et al. Regulation of rat dopamine transporter mRNA and protein by chronic cocaine admini- stration. J Neurochem 1999;73:1982-1989.

110. Kimmel HL, Carroll FI, Kuhar MJ. Withdrawal from repeated cocaine alters dopamine transporter protein turnover in the rat striatum. J Pharmacol Exp Ther 2003;304:15-21.

111. Chen N, Reith ME. Substrates and inhibitors display different sensitivity to expression level of the dopamine transporter in heterologously expressing cells. J Neurochem 2007;101:377-388.

112. Shippenberg TS, Heidbreder C, Lefevour A. Sensitization to the conditioned rewarding effects of morphine: pharmacology and temporal characteristics. Eur J Pharmacol 1996;299:33-39.

113. Steketee JD. Cortical mechanisms of cocaine sensitization. Crit Rev Neurobiol 2005;17:69-86.

114. Zahniser NR, Peris J, Dwoskin LP, Curella P, Yasuda RP, O'Keefe $\mathrm{L}$, et al. Sensitization to cocaine in the nigrostriatal dopamine system. NIDA Res Monogr 1988;88:55-77.

115. Ujike H, Tsuchida K, Akiyama K, Otsuki S. Supersensitivity of sigma receptors after repeated administration of cocaine. Life Sci 1992;51:PL31-PL36.

116. Itzhak Y, Stein I. Sensitization to the toxic effects of cocaine in mice is associated with the regulation of $N$-methyl-D-aspartate receptors in the cortex. J Pharmacol Exp Ther 1992;262:464-470.

117. Kim DS, Froelick GJ, Palmiter RD. Dopamine-dependent desensitization of dopaminergic signaling in the developing mouse striatum. J Neurosci 2002;22:9841-9849.

118. Fang Y, Ronnekleiv OK. Cocaine upregulates the dopamine transporter in fetal rhesus monkey brain. J Neurosci 1999; 19:8966-8978.

119. Daws LC, Callaghan PD, Morón JA, Kahlig KM, Shippenberg TS, Javitch JA, et al. Cocaine increases dopamine uptake and cell surface expression of dopamine transporters. Biochem Biophys Res Commun 2002;290: 1545-1550.

120. Mash DC, Pablo J, Ouyang Q, Hearn WL, Izenwasser S. Dopamine transport function is elevated in cocaine users. $J$ Neurochem 2002;81:292-300.

121. Kahlig KM, Galli A. Regulation of dopamine transporter function and plasma membrane expression by dopamine, amphetamine, and cocaine. Eur J Pharmacol 2003;479: 153-158.

122. Cerruti C, Pilotte NS, Uhl G, Kuhar MJ. Reduction in dopamine transporter mRNA after cessation of repeated cocaine administration. Brain Res Mol Brain Res 1994;22:132-138.

123. Leslie CA, Robertson MW, Jung AB, Liebermann J, Bennett JP Jr. Effects of prenatal cocaine exposure upon postnatal development of neostriatal dopaminergic function. Synapse 1994;17:210-215.

124. Stadlin A, Choi HL, Tsang D. Postnatal changes in [3H]mazindol-labelled dopamine uptake sites in the rat striatum following prenatal cocaine exposure. Brain Res 1994;637:345-348.

125. Collins LM, Meyer JS. Prenatal cocaine alters dopamine transporter binding in postnatal day 10 rat striatum. Synapse 1996;23:335-343.

126. Tella SR, Ladenheim B, Andrews AM, Goldberg SR, Cadet JL. Differential reinforcing effects of cocaine and GBR12909: biochemical evidence for divergent neuroadaptive changes in the mesolimbic dopaminergic system. J Neurosci 1996;16:7416-7427.

127. Little KY, Elmer LW, Zhong H, Scheys JO, Zhang L. Cocaine induction of dopamine transporter trafficking to 
the plasma membrane. Mol Pharmacol 2002;61:436-445.

128. Zahniser NR, Doolen S. Chronic and acute regulation of $\mathrm{Na}+/ \mathrm{Cl}$ - -dependent neurotransmitter transporters: drugs, substrates, presynaptic receptors, and signaling systems. Pharmacol Ther 2001;92:21-55.

129. Cowell RM, Kantor L, Hewlett GH, Frey KA, Gnegy ME. Dopamine transporter antagonists block phorbol esterinduced dopamine release and dopamine transporter phosphorylation in striatal synaptosomes. Eur J Pharmacol 2000;389:59-65.

130. Torres GE, Caron MG. Approaches to identify monoamine transporter interacting proteins. $J$ Neurosci Methods 2005; 143:63-68.

131. Torres GE, Yao WD, Mohn AR, Quan H, Kim KM, Levey $\mathrm{AI}$, et al. Functional interaction between monoamine plasma membrane transporters and the synaptic PDZ domaincontaining protein PICK1. Neuron 2001;30:121-134.

132. Carneiro AM, Ingram SL, Beaulieu JM, Sweeney A, Amara SG, Thomas SM, et al. The multiple LIM domaincontaining adaptor protein Hic-5 synaptically colocalizes and interacts with the dopamine transporter. J Neurosci 2002;22:7045-7054.

133. Lee KH, Kim MY, Kim DH, Lee YS. Syntaxin $1 A$ and receptor for activated $C$ kinase interact with the $N$-terminal region of human dopamine transporter. Neurochem Res 2004:29:1405-1409.

134. Dickinson SD, Sabeti J, Larson GA, Giardina K, Rubinstein M, Kelly MA, et al. Dopamine D2 receptordeficient mice exhibit decreased dopamine transporter function but no changes in dopamine release in dorsal striatum. J Neurochem 1999;72:148-156.

135. Lee FJ, Pei L, Moszczynska A, Vukusic B, Fletcher PJ, Liu F. Dopamine transporter cell surface localization facilitated by a direct interaction with the dopamine D2 receptor. EMBO J 2007;26:2127-2136.

136. Torres GE, Gainetdinov RR, Caron MG. Plasma membrane monoamine transporters: structure, regulation and function. Nat Rev Neurosci 2003;4:13-25.

137. Cook EH Jr, Stein MA, Krasowski MD, Cox NJ, Olkon $\mathrm{DM}$, Kieffer JE, et al. Association of attention-deficit disorder and the dopamine transporter gene. Am J Hum Genet 1995;56:993-998.

138. Waldman ID, Rowe DC, Abramowitz A, Kozel ST, Mohr $\mathrm{JH}$, Sherman SL, et al. Association and linkage of the dopamine transporter gene and attention-deficit hyperactivity disorder in children: heterogeneity owing to diagnostic subtype and severity. Am J Hum Genet 1998;63:1767-1776.

139. Madras BK, Fahey MA, Goulet M, Lin Z, Bendor J, Goodrich C, et al. Dopamine transporter (DAT) inhibitors alleviate specific parkinsonian deficits in monkeys: association with DAT occupancy in vivo. J Pharmacol Exp Ther 2006;319:570-585.

140. Rodriguiz RM, Chu R, Caron MG, Wetsel WC. Aberrant responses in social interaction of dopamine transporter knockout mice. Behav Brain Res 2004;148:185-198.

141. Tillerson JL, Caudle WM, Parent JM, Gong C, Schallert $\mathrm{T}$, Miller GW. Olfactory discrimination deficits in mice lacking the dopamine transporter or the D2 dopamine receptor. Behav Brain Res 2006;172:97-105.

142. Kavelaars A, Cobelens PM, Teunis MA, Heijnen CJ. Changes in innate and acquired immune responses in mice with targeted deletion of the dopamine transporter gene. $J$ Neuroimmunol 2005;161:162-168.

143. Wang GJ, Volkow ND, Fowler JS, Fischman M, Foltin R, Abumrad NN, et al. Cocaine abusers do not show loss of dopamine transporters with age. Life Sci 1997;61:10591065.

144. Carroll FI, Howell LL, Kuhar MJ. Pharmacotherapies for treatment of cocaine abuse: preclinical aspects. J Med Chem 1999;42:2721-2736.

145. Mead AN, Rocha BA, Donovan DM, Katz JL. Intravenous cocaine induced-activity and behavioural sensitization in norepinephrine-, but not dopamine-transporter knockout mice. Eur J Neurosci 2002;16:514-520.

146. Howell LL, Wilcox KM. The dopamine transporter and cocaine medication development: drug self-administration in nonhuman primates. J Pharmacol Exp Ther 2001;298: $1-6$.

147. Ginsburg BC, Kimmel HL, Carroll FI, Goodman MM, Howell LL. Interaction of cocaine and dopamine transporter inhibitors on behavior and neurochemistry in monkeys. Pharmacol Biochem Behav 2005;80:481-491.

148. Lile JA, Morgan D, Birmingham AM, Davies HM, Nader MA. Effects of the dopamine reuptake inhibitor PTT on reinstatement and on food- and cocaine-maintained responding in rhesus monkeys. Psychopharmacology (Berl) 2004; 174:246-253.

149. Gulley JM, Hoover BR, Larson GA, Zahniser NR. Individual differences in cocaine-induced locomotor activity in rats: behavioral characteristics, cocaine pharmacokinetics, and the dopamine transporter. Neuropsychopharmacology 2003;28:2089-2101.

150. Briegleb SK, Gulley JM, Hoover BR, Zahniser NR. Individual differences in cocaine- and amphetamineinduced activation of male Sprague-Dawley rats: contribution of the dopamine transporter. Neuropsychopharmacology 2004;29:2168-2179.

151. Volkow ND, Wang GJ, Fischman MW, Foltin RW, Fowler JS, Abumrad NN, et al. Relationship between subjective effects of cocaine and dopamine transporter occupancy. Nature 1997;386:827-830.

152. Venton BJ, Seipel AT, Phillips PE, Wetsel WC, Gitler D, Greengard $\mathrm{P}$, et al. Cocaine increases dopamine release by mobilization of a synapsin-dependent reserve pool. J Neurosci 2006;26:3206-3209. 